\title{
HEALTH INFORMATION SYSTEM AS CORRELATE OF MONITORING AND EVALUATION OF PRIMARY HEALTH CARE SERVICES IN IFE CENTRAL LOCAL GOVERNMENT AREA, ILE- IFE, OSUN STATE, NIGERIA
}

\author{
${ }^{1}$ Kayode Sunday Osundina and ${ }^{2}$ Adegbesan Bola \\ Health Information Management Dept., Lead City University Ibadan \\ Corresponding Author's E-mail: kayodeosundina@yahoo.com
}

\begin{abstract}
This study examines "The relevance of Health Information System in Monitoring and Evaluation of Health Care Delivery Services Ife Central Local Government, Ile-Ife. The research design used in this study was descriptive survey to provide necessary database on the relevance of Health Information System in the monitoring and evaluation of health care delivery services in Local Government Primary Health Care System, the researcher uses Ife Central Local Government, Ile-Ife, Osun State. The target population consists of one hundred and twenty (120) respondents (Staff of Primary Health Care Department of Ife Central Local Government, Ile-Ife). Sampling technique adopted for this study is total enumeration, all the staffs of Health Information Management Department were used for the research because the researcher considers these respondents as a genuine unit where all important and detailed information could be obtained for this research work. In the course of data collection exercise, a total of one hundred and twenty questionnaires were administered. The questionnaires were administered at the various units of the Primary Health Care Department of Ife Central Local Government and one hundred and fourteen questionnaires were completed and returned questionnaire which denotes the response rate to be $95 \%$ which proved that there is sufficient information from the respondents. From the findings of the study, it was discovered that health information system is effective due to the opinion of majority of the respondents which denotes that health information system contributes to good service delivery in Primary Health Care settings. It was affirmed that there are factors hindering effective management of health information system by the respondents which was supported by $75.5 \%$ of them in their response to question 24 of the questionnaire. HIS has benefits on health care monitoring and evaluation which denotes it can be used in policy and decision making. It was also proved according to responses to question 21 of the questionnaire that the duties of the health information officers cannot be overruled and that they play their roles as expected for generation and utilization of health information. It was observed too that health information is being put into use regularly for monitoring and evaluation of health care service by the respondents in question number 20 of the questionnaire. This study reveals that Health Information System has great impact on healthcare service delivery, the system captures, transmits and stores information related to patient care and the activities of the health institution. It incorporates routine information system, disease surveillance system, laboratory information system, hospital patient administrative system which is used to process reports and create awareness in order to make policy action programmes effective for quality monitoring and evaluation activities and the recommendations that were made includes: The provision of sufficient and well trained staff, training and seminar, caution against paucity in information gathering, adequate funding, setting up supervisory committee and computerization of various sections.
\end{abstract}




\section{INTRODUCTION}

Health Information System (HIS) can be defined as "a set of components and procedures organized with the objective of generating information which will improve healthcare management decisions at all levels of the healthcare system" (Lippeveld, Sauerborn, and Bodart, 2000).

Sound and reliable information is the foundation of decision making across all health system building blocks, and is essential for health system policy development and implementation, governance and regulation, health research, human resources development, health education and training, service delivery and financing. The health information system provides the underpinnings for decision making and has four key functions: data generation, compilation, analysis and communication (World health organization, 2008).

The health information system collects data from the health sector and other relevant sectors, analyses the data and ensures their overall quality, relevance and timeliness, and converts data into information for health related decision making. The health information system is sometimes equated with monitoring and evaluation but this is too large as a perspective. In addition to being essential for monitoring and evaluation, the information system also serves broader ends, providing an alert and early warning capability, supporting patient and health facility management, enabling planning, supporting and stimulating research, permitting health situation and trends analysis, supporting global reporting, and underpinning communication of health challenges to diverse users. Information is of little value if it is not available in formats that meet the needs of multiple users; policy makers, planners, managers, health care providers, communities and individuals. Therefore, dissemination and communication are essential attributes of the health information system (World health organization, 2008).

Health planners and decision makers need different kinds of information including:

- Health determinants (socio-economic, environmental behavioural, genetic factors) and the contextual environments within which the health system operates.

- Inputs to the health system and related processes including policy and organization, health infrastructure, facilities and equipment, costs, human and financial resources, health information systems.

- The performance or outputs of the health system such as availability, accessibility, quality and use of health information and services, responsiveness of the system to user needs, and financial risk protection.

- Health outcomes (mortality, morbidity, disease outbreaks, health status, disability, wellbeing).

- Health inequities, in terms of determinants, coverage of use of services, and health outcomes, and including key stratifiers such as sex, socio-economic status, ethnic group, geographical location etc (world health organization, 2008).

A good health information system brings together all relevant partners to ensure that users of health information have access to reliable, authoritative, usable, understandable, comparative data (world health organization, 2008).

It is widely accepted that health managers and service providers need better access to reliable information and better ways to use this information to monitor performance and 
manage service. The effective management of the entire health systems depends on the appropriate use of timely and accurate information by personnel at all levels. The use of this information depends on the ability of the health information system to generate useful information.

Information collection at the health facility and by the health teams to monitor the progress made, and identifying the weakness, thereby taking necessary remedial actions by using the appropriate indictors which help to improve the management and activities of the health facility. Information systems have great potential to reduce healthcare costs and improve outcomes. This is detected by exploring the role of information in the delivery of healthcare in its diverse organizational and regulatory settings (Lemay, 2010).

Monitoring and evaluation system is a mechanism for collection of health information to facilitate decision making in the efficient and effective management of the health care and means of measuring the status of health of the community and population coverage but it's also a form of management information system. The effectiveness of any information system depends on the quality of data being collected, who collects the data, timeliness of the information and the use of the information. Data is not just collected just for its sake; rather, it is for assessing the adequacy, processing efficiency, effectiveness and impacts of the health services and programmes on the health and quality of life of the population.

Monitoring and evaluation has to be kept in mind and ensure that the data collected are accurate; timely and relevant to all who need them at various levels of an health care deliveries for the purpose of planning, management and evaluation.

A good monitoring system gives the critical information to manage the intervention and take prompt corrective action. An evaluation cannot give you this type of information gained from monitoring system therefore; a manager is usually driving it because he or she needs actionable monitoring information. And this actionable information is the data that can be used to make a decision and take action. It helps to identify the gaps in the performance and find ways to fill the gaps. The information gained from monitoring must be based on useful indicators produced in a simple format that is on time for planning. These indicators must be useful and directly related to the organizational plans and the expected results. Indicators of data generation reflect health care capacity to collect relevant data at appropriate intervals and using the most appropriate data sources. Benchmarks include periodicity, timeliness, and contents of data collection efforts and availability of data on key indicators. Indicators of health care capacity measure key dimensions of the institutional frameworks needed to ensure data quality including transparency and accessibility. Benchmarks include the availability of coordination mechanisms, and the availability of data.

An indicator is a variable that measures one aspect of a health program. The monitoring and evaluation (M\&E) team uses indicators for monitoring health programs to show that program activities are being carried out as planned and evaluating health programs to show that a program activity has caused a change in a particular behaviour or health outcome.

Statistical indicators can suggest issues for healthcare performance management, quality improvement and further scrutiny; however, they need to be interpreted with caution. Much of the current evidence on the effective of performance indicators is based on observational or experimental data. Some experiences suggest that indicators such as guidelines to standardize management of common conditions may reduce length of stay and episode costs 
without detriment to clinical outcome. The publication of health care performance statistics should aims to encourage improvement, to empower patient choice and to demonstrate a commitment to transparency. Evidence suggests that this increases public interest and management attention to data quality, but it does not appear to have much effect on performance.

The design of health care performance measurement systems should aim to improve hospital performance, rather than to identify individual failures. Systems should not rely on single sources of data but should use a range of information. Consumers should be prominently involved, and the results of assessments should be transparent and freely accessible to the public.

\section{Statement of Problem}

Health care personnel could not achieve much without a feedback from the public due to inadequate health information reporting. There is insufficient data to facilitate decision making and the inability to implement computer based record in gathering of patient information and also for communication purpose and to bring about gathering of adequate data.

\section{Objective of the Study}

The objectives of this study are to:

I. Examine the relevance of health information system in the monitoring and evaluation of health care service delivery.

II. Highlight the basic health information system in monitoring and evaluation of health care services in Ife Central Local Government Area.

III. Mention the factors hindering health information system as an indicator for monitoring and evaluation of health care series.

IV. Identify effectiveness of health information system in health care delivery service.

V. Identify the impact of Health Information Managers in health care services.

\section{Research Questions}

I. How relevant is health information system in primary health care services of Ife Central Local Government Area?

II. What are the factors hindering effective management of health information system?

III. What are the benefits of health information system in a health care monitoring and evaluation?

IV. What are the importance of health indicators in monitoring and evaluation?

V. What are the duties of health information officers in health information generation and utilization? 
VI. How often is health information being put into use for monitoring and evaluation of health care services?

\section{REVIEW OF RELATED LITERATURE}

\section{Health Information System}

Health information system (HIS) refer to any system that captures, stores, manages or transmits information related to the health of individuals or the activities of organizations that work within the health sector (Pacific Network 2011).

This definition incorporates things such as district level routine information system, disease surveillance system, and also includes laboratory information systems, hospital patient administration system (PAS) and human resource management information systems (HRMIS). Overall, a well-functioning HIS is an integrated effort to collect, process, report and use health information and knowledge to influence policy and decision-making, programme action, individual and public health outcomes, and research. Sound decisionmaking at all levels of a healthcare system requires reliable health statistics that are disaggregated by sex, age and socioeconomic characteristics. At a policy level, decisions informed by evidence; contribute to more efficient resource allocation and, at the delivery level, information about the quality and effectiveness of services can contribute to better outcomes (Pacific Health Information Network, 2011).

Aremu (2006) defined health information as a clinical, scientific, administrative and legal document relating to patient care which contains sufficient data written in the sequence of events to justify the diagnosis and warrant the treatment and end result. As a document, health information is not only repository of information, it is continue record which acts as a means of communicating between members of the health team. The health information managers must cooperate with the doctors, nurses other health team in order to complete the patient health information quickly. Also, the knowledge of medical and paramedical specialist are needed to give complete care to the patient, it is important that there must be prompt recording of observation, treatment and care by all the staff that contributed to the treatment rendered to the patient.

Huffman (1985) opined that health information is a compilation of pertinent fact about a patient. The patient health information must be compiled at the appropriate time and must also entail adequate data to identify the patient, contributes to help diagnose and give necessary treatment as a result of accurate documentation. The patient health records must contain necessary forms which must be standardized for appropriate use.

Osundina (2008) also sees health information as a device for recording the significant characteristics of a patient and his illness and the event occurring in the course of professional care for the purpose of providing the best medical care to the patient and for teaching, research study, legal requirement, and appraisal of medical practice.

In acquiring health information or generating health data, health records serves as an important source of data for continuous health services reporting system and for reporting to ad hoc requests. For the information to be effectively and efficiently use, the generation of health information like collection, collation, compilation and analysis of data from health 
records should be monitored to ensure accuracy and completeness also to be reliable and relevant (Renuka Bery in balantyne, 2002).

The performance of health information system is linked not only to technical determinants such as data quality, system design or adequate use of information technology. Some other determinants includes organizational and environmental determinants that relates to the structure of the health information system, the roles and responsibilities and the available resources for health information system and the behavioural determinants such as skills, knowledge, attitudes and motivation of those involved in the collection, collation, analysis and dissemination of information system (Lafond and Field, 2003).

At the beginning, computer supported health information systems were primarily intended to support health care professionals, mainly physicians, and also administrative staff in the hospitals (Reichertz, 1984; Ball, 1971).

But it was later focused on nurses and since then health information systems has been directed to support patients, their relatives and other health care customers (Ball, Garets, Handler, 2003).

Health information management professionals plan information systems, develop health policy, and identify current and future information needs. Also, they may apply the science of informatics collection, storage, use and transmission of information to meet legal, professional, ethical and administrative records-keeping requirements of health care delivery (World Health Organization, 2010) and they work with clinical, epidemiological, demographic, financial and coded health data.

Stansfield (2005) suggested that proper collection, management and the use of information within health care systems will determine the system effectiveness in detecting health problems, defining priorities, identifying innovative solutions and allocating resources to improve health outcome.

\section{Legal requirement of a Health Information System}

There should be an health information department with adequate space, equipment and trained personnel, accurate and complete health record must be written to all patient and all completed health information should include identification, sociological and clinical data to justify the diagnosis and warrant to treatment given. Also health information must be in an accessible manner in a secured place in the hospital (Omole, 2013).

\section{Health Information System as a requirement in Health Care Service Delivery}

The world health organization defined health as a state of complete physical, mental and social wellbeing of a person not merely in the absence of disease and infirmity. Health information technology (HIT) is "the application of information processing involving both computer hardware and software that deals with the storage, retrieval, sharing and use of health care information, data, and knowledge for communication and decision making" (Brailer, \& Thompson, 2004). 
Health care facility are built and maintain for the benefit of the patients, failure to retain accurate, timely and complete health information results in negligence in the institutional responsibility to patients and the community as a whole, for adequate records generate vital statistics for society review, planning and allocating of health care resources. Good health information is essential for rendering efficient patient care at minimum cost. Therefore increasing attention is scientifically formulated health information does not only provides vital statistical information but assists the efficient provision of patients care and enables the analysis of the quality of patients care services the reason why health information is required in an health care delivery are:

For patient use: Health information present all details about the health status of a patient since the beginning of clinical consultation to the end, it analyses the ailment in terms of diagnosis and prognosis, consultative opinion, which serve as reference of old record, it enables the doctors to identify previous ailments and gives insight in treatment of the patients. Allergies and drug reactions are noted, previous surgical procedures are recorded, protection from over-prescription, unnecessary surgical exploration and repetition of investigation and protection from legal action.

For physician use: It helps to inquire information about previous treatment, reactions to drugs, allergies, drug investigations, mode of treatment and care results and also suggest new lines of investigation and treatment, evaluation of drugs for their clinical effects, information about the availability of new drugs for patient use, comparative studies, medico legal purpose, for teaching and research purpose.

Health care delivery: Health information evaluates the competency of medical, nursing and other health workers, it justifies result of treatment, exposes in malpractice, medico-legal purpose, and it is also used in administrative control, for preparing operating budget, distribution of expenses when computing, it provides cost of operations, statistical data help in controlling bed allocation, available bed, occupied beds, mortality, infection and length of stay it plans additional facilities, staff, equipment and improved health education.

For research purpose: Health information of the past and present help, prospective and retrospective research, it helps to learn an easier way to deal with problems and control healthcare cost. It also assists to generate new techniques and new medications to conduct research.

\section{Meanings of monitoring, evaluation and pointer (indicator)}

According to (Shapiro, Janet, 2010) The term "monitoring and evaluation" tends to get run together as if it is only one thing, monitoring and evaluation are, in fact, two distinct sets of organizational activities, related but not identical.

Monitoring is the systematic collection and analysis of information as a project progresses. It is aimed at improving the efficiency and effectiveness of an organization. It is based on targets set, and activities planned, during the planning phases of work. It helps to keep the work on track, and can let management know when things are going wrong. If done properly, it is an invaluable tool for good management, and it provides a useful base for evaluation. It helps to determine whether the resources available are sufficient and are being well used, whether the capacity available is sufficient and appropriate plan is been executed. 
Evaluation is the comparison of actual project impacts against the agreed strategic plans. It looks at what it been set out to do, at what is to be accomplished, and how to accomplished. It can be formative (taking place during the life of a project or organization). It can also be summative (drawing learning from a completed project or an organization that is no longer functioning). What monitoring and evaluation have in common is that they are geared towards learning from what you are doing and how you are doing it, by focusing on: Efficiency, Effectiveness, Impact.

Efficiency tells that the input into the work is appropriate, in terms of the output. This could be input in terms of money, time, staff, equipment and so on. When a project is executed and it's concerned about its replicability or about going to scale then it is very important to get the efficiency element right.

Effectiveness is a measure of the extent to which a development programmes achieves that is to be addressed.

Impact describes whether or not what was done make a difference to the problem situation that is to be addressed.

Therefore, monitoring and evaluation involve continuous and periodic assessment of the health care delivery in order to know whether it is proceeding according to the aim and objective of the health institution (Dr. Verentson and Co., monitoring and evaluation manual 1992).

\section{Pointer (indicator)}

Indicators are measurable or tangible signs that something has been done or achieved. Indicators are also dealt with in overview of planning and in the section of monitoring and evaluation process (Olive, 1996). In some studies, for example, a decreased number of infant mortality in a hospital has been used as an indicator that the standard of care in the hospital has improved.

According to Osundina (2008) indicators as the process of providing data to measure changes in the health situation and health status which gives access to progress toward attainment of objectives. The level of indicator explains how close to, or how far away from a particular programme is to achieve its objectives. Examples of indicators include the following:

- Death rate, Life expectancy at birth, Infant mortality rates Causes of death, Number of hospital beds, Birth rate, ,Fertility rate ,Infant mortality rate, Immunization rate etc.

\section{The Uses of Health Information in Monitoring and Evaluation of Health Care Delivery Services}

Adediran (2010) posited that, the quality of health care of an institution is measured by its health information. Proper health staff organization is the only means by which quality care can be assured. Health information may be terms as any patient information and documents kept in a systematic, scientific and easy ways that help to receive the required data at the time of necessity. Similarly, it is also a systematized way of storing the required data, information and other relevant documents with the objective of making easy availability of necessary data at the time of its need. Health data consists of name of patient, address, age, 
sex, occupation, disease, modes of diagnosis and recommendations made the after by the concerned doctor in course of undergoing treatment. It helps patients to acquire the right and apt treatment. Moreover, it acts as a tool for the doctor who is looking into the patient disease.

When we talk of the development of health information, we have to go back to the seventeenth century. In 1752 A.D. Benjamin Franklin set up an incorporated Hospital in Philadelphia in United State of America. This hospital is presently known as Pennsylvania Hospital. He introduced medical record by preparing file of special cases on which patients' name, admission date, discharge date etc. were written. In the same way, another hospital was opened in Boston in 1821 A.D. where a typical method of keeping relevant data was initiated. Separate files were opened for different individual patients in order to keep records. This process proved to be more helpful in finding the necessary data regarding the patients. Besides this, it helped in acquiring important facts that could make it easier to take care for patients and to conduct proper research work.

With the passage of time health information has been a backbone for developing a new dimension in the health care in each of the countries in the world. It has been indispensable for health institutions to continue the research works, to deliver the appropriate health services to the patients, create the skilled manpower and to enhance the goodwill of the nation as well. Considering the significance of health information, no hospitals and health centers are opened without establishing a separate and equipped health information sections. Apart from this, provisions for impacting the required knowledge to the person working in medical record section have also been made. For this purpose, some institutions that impact special training have also been set-up.

Taking into account of importance of health information the World Health Organization has introduced International Classifications of Disease in 1946 AD with the view of integrating the proper diagnosis systems and formulating the true and factual data on the basis of health information kept by all the health entitles. WHO has initiated ICD-10 which has laid emphasis on caring for patients and finding out the causes of disease. Moreover, it tries to explain the ways to be resorted against nurse, doctor and other health workers who works under estimation and with carelessness. This helps to check the errors committed either with intention or with ignorance. In addition to this it has made provision for mentioning Morbidity, Mortality, and Cause of Death. It gives more emphasis on the injuries owing to external accidents. It has made mandatory to explain about the cause of accident and the effects it has created upon him. This provision has somewhat helped the country minimize the accidents of such kind.

It cannot undermine the relationship between the doctors of concerned authority and the people requiring medical treatment. Health information, no doubt, may be regarded as a supportive hand in such matters. It helps doctors as well as patients to get informed of the ailments and plans and procedures adopted in course of conducting treatment. Health information can also be regarded as such device that might help the governing body, health institution and person concerned, in the easily and timely availability of required information without any dilly-dally. A patient as well as doctor may derive the respective file/information in case of necessity as legal evidence. Health information therefore refers to as a complete file prepared for each patient with all clinical records. 
It acts as a means of providing necessary data in connection with the health of people and the brunt of specific diseases at the specific places to the health sectors including the nation. On the basis of good management of health information, one can easily obtain the ways of rendering services, standard of service, diagnosis pat tern, style of treatment and managerial functioning pursued thereby serving as a pointer for monitoring and evaluation of a health care. Health information plays a pivotal role in such health care, which are especially involved in research work as well as imparting health education to the people. With the help of it the standard and efficiency of the product therefore can be appraised. Besides this, one can easily ascertain the quality of service being delivered by the expertise manpower and one can easily receive data pertaining to health of people in order to conduct research work.

Since there must be a name and signature of concerned doctor who is involved in the treatment of any patient in medical record, more caution is necessarily taken, in the course of treatment. As a result of a patient may derive a right treatment after quick and meaningful diagnosis of disease. This helps not only the patients in receiving the good health but also the doctors in keeping his/her good will. A good arrangement of medical record is instrumental for the concerned bodies in understanding the pressure/concentration of patients, nature of diseases and all the personal details of patient. Due to easy access to these invaluable facts and figure the organization can make some alternations in its existing plans and policies and formulate some additional policies in case of urgency and directives so as to deliver better and more standardized service in the upcoming years.

Health information consists of notes, worthy for the health care in several aspects. Since it contains various facts like personal details of patient, illness, diagnosis, modus operandi used to find out the disease, seriousness of diseases, medicines being used by patients on the recommendation of his/her attending doctors and even the clear names and signature of attending doctors, the healthcare provider can attain the health relating information through thorough check up of such health information. Health care team can be availed of such records in the direction of making short as well as long term healthcare strategies. An integrated study of health information available in all the hospitals and health centers will contribute towards knowing the health condition of people, ailment stricken areas, cause and effects of disease, availability of health workers as well as physical facilities and resources in order to deliver the appropriate health service to the people.

Through the study of health information, preventive measures are to be timely adopted in order to save people from being ill. The reason behind it is that the epidemics and other disease tending to spread can conveniently be well informed in time. The proportion of doctors to patients, the nature of disease and its repercussions, the number of doctors associated with certain disease, urgency of specialized service and the number of beds available at certain place compared with its actual requirement and so on are some other prominent facts as can be easily through this.

\subsection{The Duties of Health Information Managers in the Health Care Delivery Services}

The need for a national health information system that will supply accurate health and demographic data for the planning, administration, monitoring and evaluation of health services has been highlighted in the national policy and strategy of 1988. 
Health information management staff (also known as Health records staff) collage, organize, retrieve and archive the record of a patient or client, for the purpose of recording and informing their care. They also record the communication of a patient's care between health professionals and ensure all legal, audit and governance requirements are met. Good interpersonal skills and an ability to maintain confidentiality are keys to roles in health information. There are categories of cadres in health information management profession and below are some examples;

Health record officer: Health record officers work with other health professionals, the role involves obtaining, validating and checking patient data before entering it into a database. The role also involves preparing patient records for filing, being responsible for ensuring that all files are maintained to the highest standard and that they are correctly booked in and out of the department. Health records and patient administration staff collate, store and retrieve records used in diagnosis and treatment, this is a critical role due to the vast number of healthcare professionals involved in a patient's care who need access to this vital information at a moment's notice. They also promote and support the effective use of data, information and improve health and the delivery of patient care. Health records officer has responsibility for specific areas within a health records department, this may include; the direct line management of the health records staff the operational management of health records in a department contributing to the development of policies, procedures and practices, relating to health records assisting in the development of health record audits. A health records officer is responsible for the overall management, performance and development of a department(s) health information service in an organization. This may include: communicating and negotiating contentious issues with senior management and clinical staff, financial planning, ensuring quality standards are maintained, provides advice and guidance to a range of people on all aspects of legislation relating to health records.

Health records technician: Undertakes routine administrative work in relation to health records, this might include: locating, retrieving, tracking and delivering patient's health records and case notes, maintaining patient records and case notes, filing patient records and case notes, maintaining patients' confidentiality and participate in audits of patient records.

Health recordsclerk: Health records clerk often work in general hospitals and may provide administrative cover, including outpatient reception and appointment booking, case note allocations, library storage and a variety of more specialized services. People working in this area need an ability to stay calm under pressure, be enthusiastic, have a basic level of computing skills and have a good general education. And we under the health records clerk, we have the admission clerks and the ward clerks.

Admission clerk: Admissions clerks take details of patients who are being admitted for treatment. People working in this area need good interpersonal skills, good typing skills, experience of using computers, communication skills and a tactful manner.

Ward clerk: Ward clerks work under the guidance, supervision and instruction of a manager and other qualified staff on the ward. This role involves maintaining paper work, using computers for record keeping and dealing with telephone queries on a ward. Good communication skills are essential to this type of work. 


\section{Relationship between Health Information System and Monitoring Evaluation}

The National Health Policy, (2004), reiterates that, the availability of accurate, timely, reliable, and relevant information is the most fundamental step towards informed public health action, and monitoring and evaluation of health care services. Also, the relationship between policy maker, service managers, communities and other stakeholders, in the monitoring and evaluation process is critical, to the success of the health care service monitoring and evaluation.

Because the dilemma that gives rise to the need for monitoring and evaluation is often, the gap between the available resources and health needs, which are identified via available information, leading to the requirement to make choice as to how to use these resources efficiently, (PHAST, 2011).

Adindu, (2008) established that, well designed and managed health information system generate reliable, relevant, accurate and understandable information, useful to decision makers for an evidence based monitoring and evaluation. Quality health information system generated from a reliable Health Management Information System, is an indispensable platform for a result oriented monitoring and evaluation. Every health organization regardless of the size and purpose needs reliable information for planning and management of their services.

She stated further that; organizational ability to effectively respond to internal and external changes and challenges, depend on the quality of available information which enables the organization to compare means with ends; actual results with planned health programmes, the quality of health series, and performance of individuals and groups. Effective response to health care needs and demands is possible where information is available in the right quality quantity, when needed to guide decisions and actions for a robust health care service monitoring and evaluation.

NPHCDA (2012) supported the above by asserting that; effective health information system is equally essential for the sustenance of health care system, because;

$>$ It promotes information for effective health service planning and implementation.

$>$ It allows timely corrective measure to be taken in the event of the programme encountering problem.

It encourages efficient use of resources and improves programme effectiveness

$>$ It promotes feedback based on empirical facts that can be used for programme review, monitoring and evaluation.

Therefore, weak, uncoordinated and the dearth of reliable data and health information system can hamper the measurement of the impact of health care services on the population, which may negatively affect health care service monitoring and evaluation activities, (Osundina, 2014). The quality of any health care service monitoring and evaluation in any Nation depends on the quality and quantity o relevant health information that is available to the policy makers, through the National Health Management Information System. Therefore government at all level should ensure standardization and financing of health data infrastructure, especially with respect to establishing and strengthening relevant organizational structures for Health Management Information System in Nigeria. 


\section{Appraisal of Literature}

In the course of the study, inferences were drawn from existing literatures and postulated models that, there is significant influence of Health Information System on the monitoring and evaluation of health care services. NHMIS policy (2006), confirmed this by reporting that; the availability of accurate, timely, reliable, and relevant health information is the most fundamental step towards informed public health action.

Therefore, for effective management of health and health resources, government at all level have overriding interest in supporting and ensuring the availability of health data and information as a public goods for public, private, and non-governmental organizations (NGOs) utilization. The role of government must extend to ensuring the standardization, digitization, dissemination and adequate funding of the National Health Information System in Nigeria in order to promote effective health care service monitoring and evaluation.

\section{METHODOLOGY}

The research design method used in this study was descriptive survey. The researcher uses PHC Department of Ife Central Local government, Ile-Ife, Osun State. The target population consists of one hundred and twenty (120) respondents (Staff of PHC Department of Ife Central Local Government).

Sampling technique adopted for this study is total enumeration that is: all the staff of PHC Department of Ife Central Local Government Area were used for the research because the researcher considers these respondents as a genuine unit where all important and detailed information could be obtained for this work. The researcher used a structured a questionnaire for the collection of information from the respondents.

\section{Ethical Consideration}

The researcher explained the aim of the research and assured the respondents that all information supplied shall be used for academic purposes and that it shall be treated as strictly confidential.

\section{Data presentation, analysis and discussion of findings}

Six research questions were posed and analyzed using the simple percentage analysis and then presented in tables and charts.

In the course of data collection exercise, a total of one hundred and twenty questionnaires were administered. The questionnaires were administered at the various units of Primary Health care Department of Ife Central Local government. The one hundred and fourteen completed and returned questionnaires denote the response rate to be $95 \%$ which proofed that there is sufficient information from the respondents. 


\section{Section B: Research question analysis}

Research question 1: How effective is health information systems Ife Central Local Government?

Table 8: How effective is health information systems in Ife Central Local Government?

Variable

Very effective 21

Partially effective 14

68

11

114

Total
Percentage

18.4

12.3

59.7

9.6

100
Cumulative percentage

18.4

30.7

90.4

100

Source: Administered questionnaire (2016)

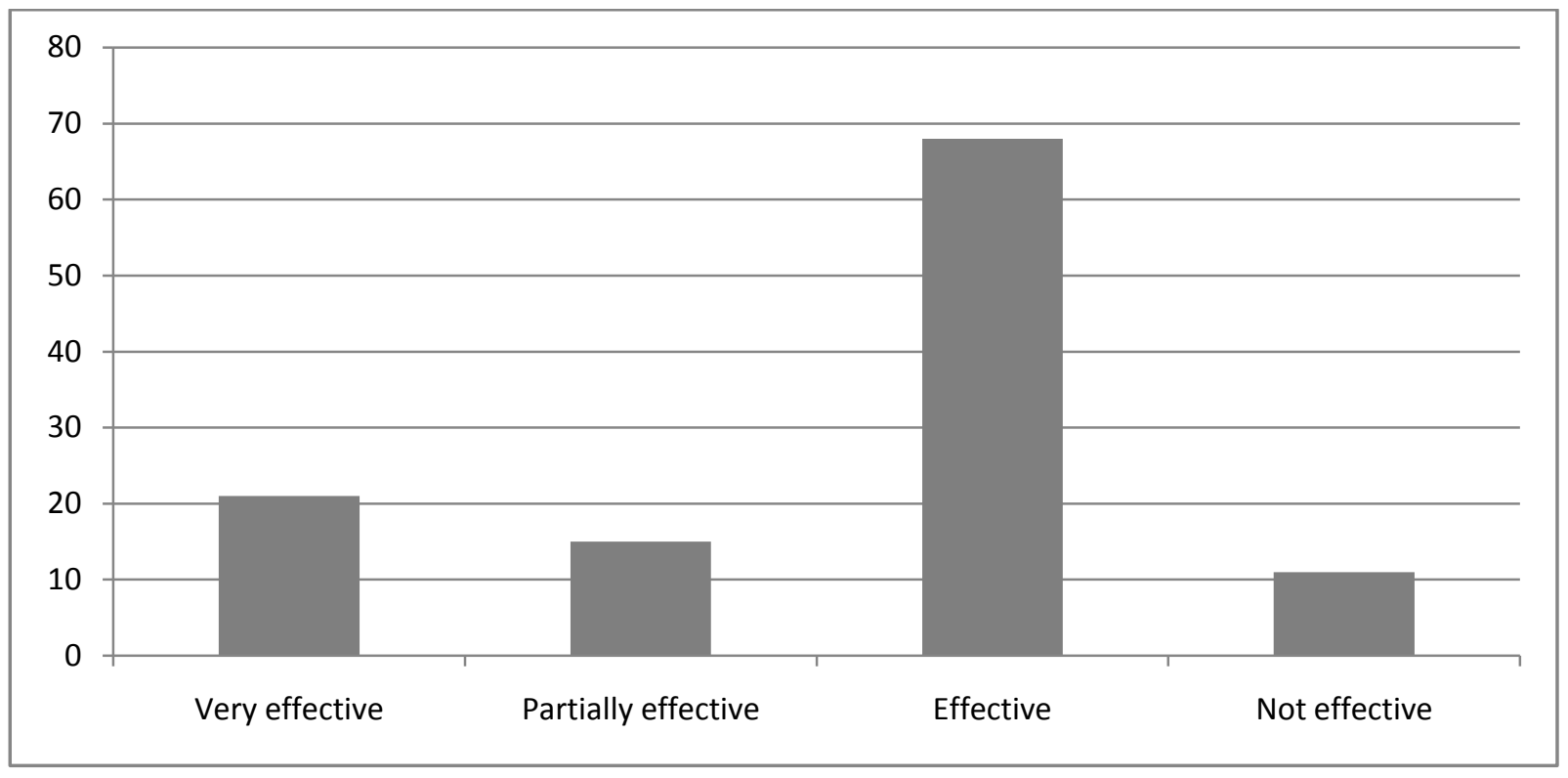

The Table and the column chart above show that most of the respondents $68(59.7 \%)$ responded that health information systems is very effective at Ife Central Local Government, $14(12.3 \%)$ responded that it is partially effective, $21(18.4 \%)$ responded that it is effective, $11(9.6 \%)$ responded that it is not effective. This response rate denotes that health information systems in Ife Central Local Government is effective which means that it will contributes to good service delivery and thereby serves as pointer for monitoring and evaluation of the health care.

Research question 2: Are there factors hindering effective management of health information systems? 
Table 9: The percentage distribution showing the response to question 24

$\begin{array}{llll}\text { Variable } & \text { Frequency } & \text { Percentage } & \begin{array}{l}\text { Cumulative } \\ \text { percentage }\end{array} \\ \text { Yes } & 86 & 75.5 & 75.5 \\ \text { No } & 12 & 10.5 & 86.0 \\ \text { Not sure } & 16 & 14.0 & 100 \\ \text { Total } & 114 & 100 & \end{array}$

Source: Administered questionnaire (2016)

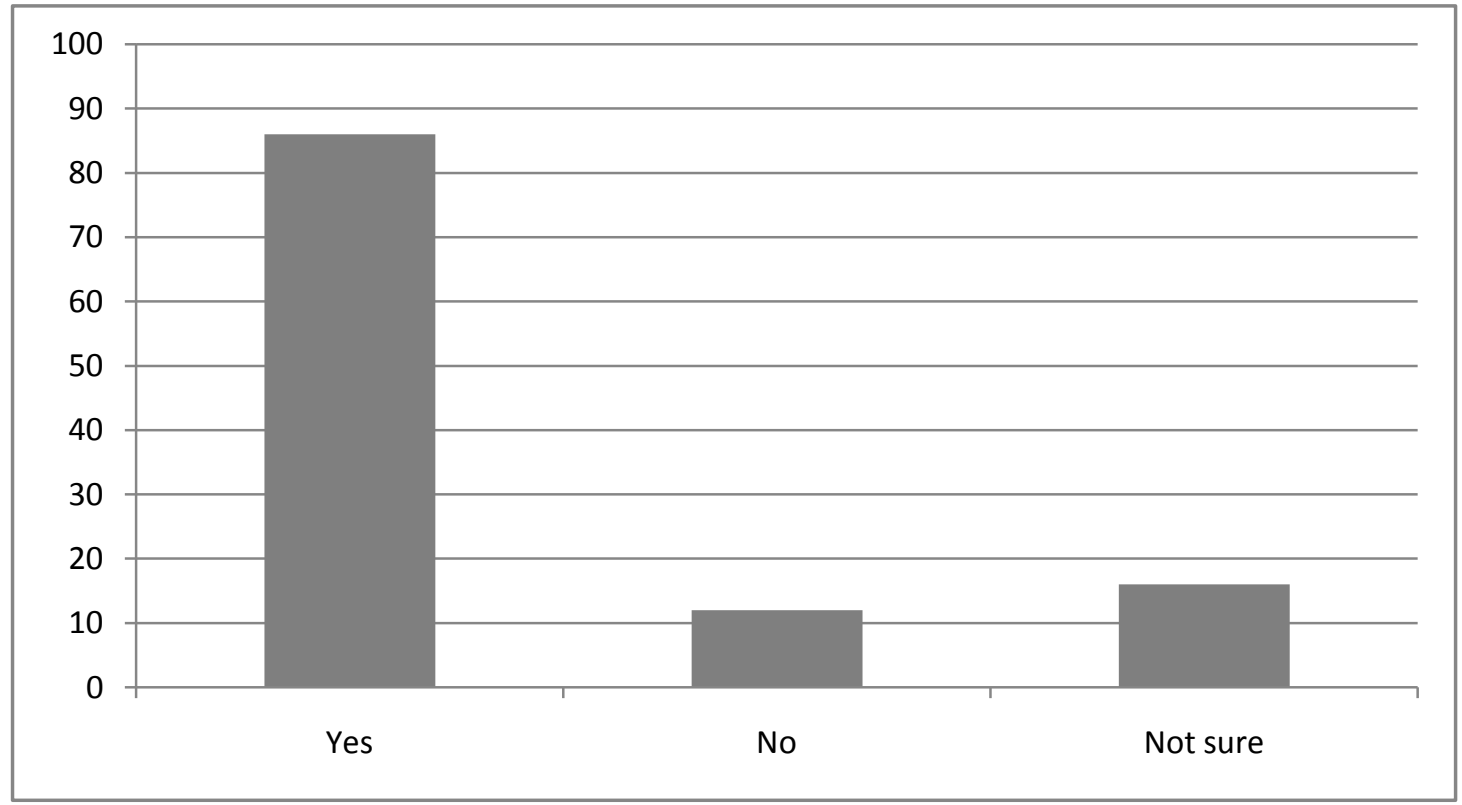

From the above table and column chart, 86(75.5\%) respondents confirmed that there are factors hindering effective management of health information systems, $12(10.5 \%)$ did not while $16(14.0 \%)$ were not sure.

Research question 3: What are the benefits of health information systems in health care monitoring and evaluation? 
Table 10: Percentage distribution showing the response to question number 16

Variable Frequency Percentage Cumulative percentage

Yes 109 95.6 95.6

No 2

Not sure 3

2.6

100

Total

100

Source: Administered questionnaire (2016)

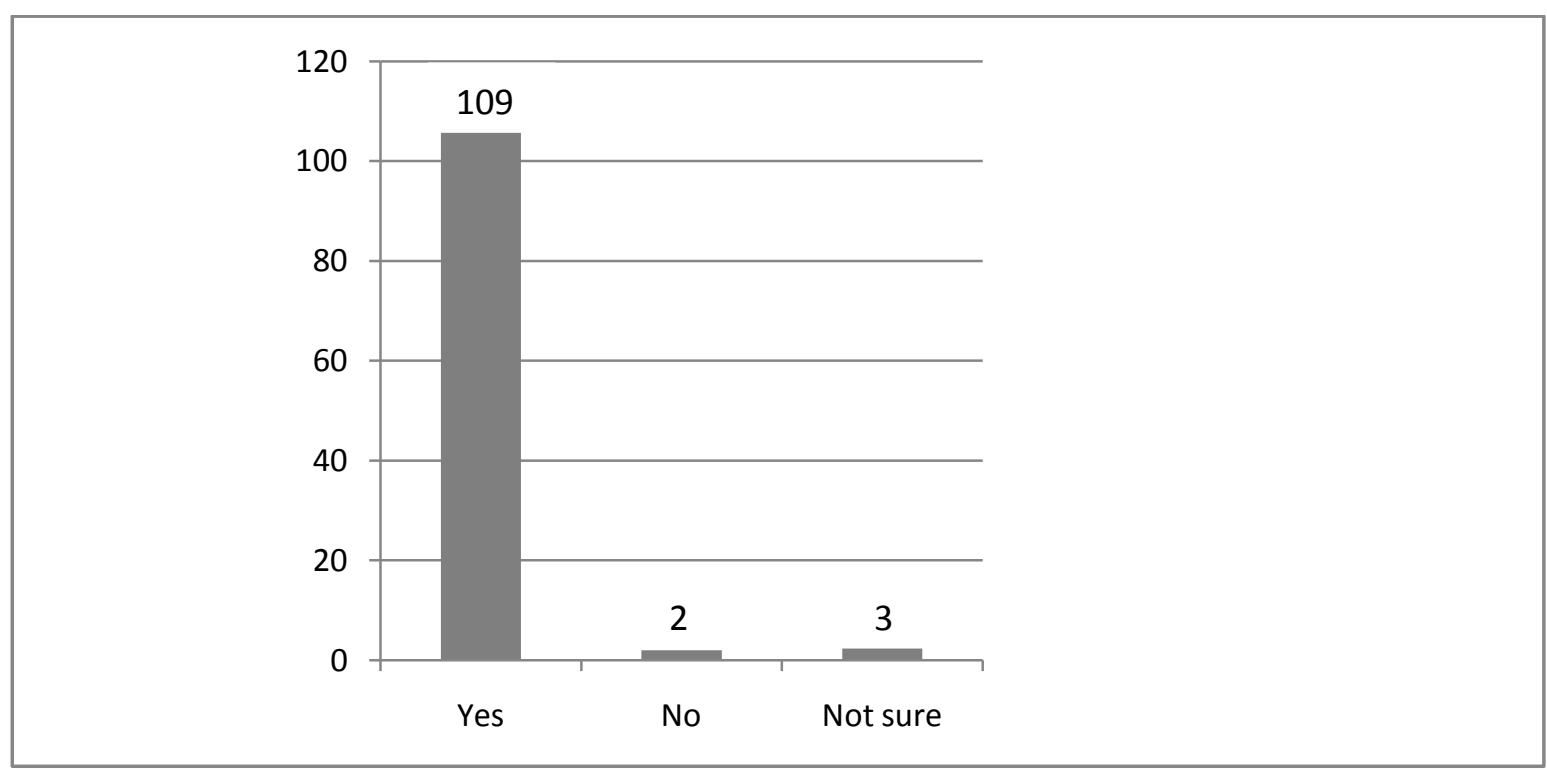

From the above table and column chart, the largest percentage of the respondents 109(95.6\%) opined that there are benefits of health information systems in monitoring and evaluation, $2(1.8 \%)$ of the respondents opined that there is no benefit and $3(2.6 \%)$ were not sure. The response rate denotes that there are benefits in health information systems for health care monitoring and evaluation.

Research question 4: What are the importance of health indicators (pointers) in monitoring and evaluation of health care services? 
Table 11: The percentage distribution below shows the response to question number 23

$\begin{array}{llll}\text { Variable } & \text { Frequency } & \text { Percentage } & \begin{array}{l}\text { Cumulative } \\ \text { percentage }\end{array} \\ \text { Yes } & 102 & 89.5 & 89.5 \\ \text { No } & 7 & 6.1 & 95.6 \\ \text { Not sure } & 5 & 4.4 & 100 \\ \text { Total } & 114 & 100 & \end{array}$

Source: Administered questionnaire (2016)

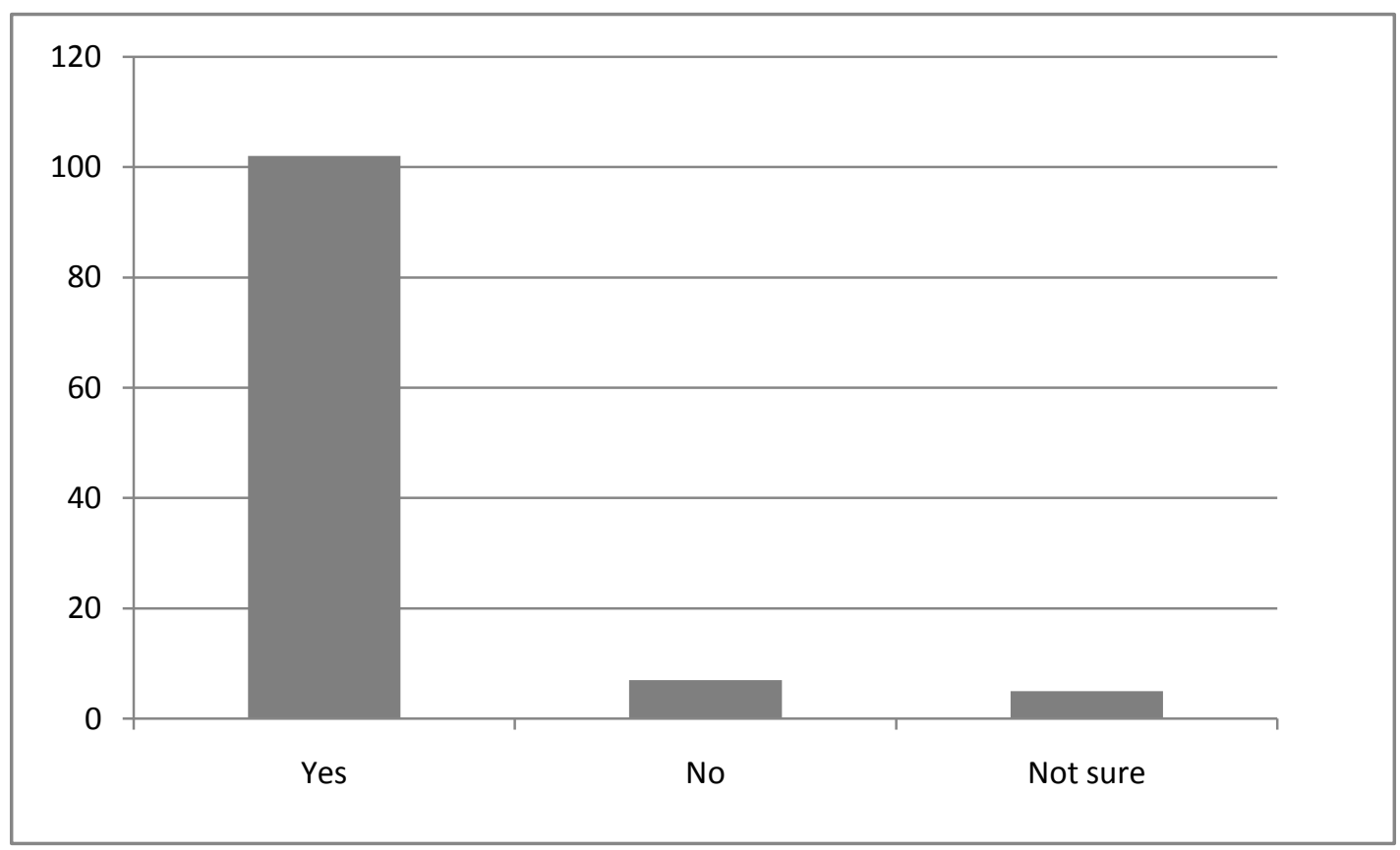

The table and column chart above revealed that $102(89.5 \%)$ of the respondents opined that health indictors (pointers) facilitate accurate measurement of health care service monitoring and evaluation system, 7(6.1\%) of the respondents didn't while 5(4.4\%) were not sure. The response rate asserted that health indicators have significant importance in monitoring and evaluation of health care delivery service.

Research question 5: What are the duties of health information officers in health information generation and utilization? 
Table 12: The percentage distribution below shows the response according to question number 21 .

$\begin{array}{llll}\text { Variable } & \text { Frequency } & \text { Percentage } & \begin{array}{l}\text { Cumulative } \\ \text { percentage }\end{array} \\ \text { Yes } & 97 & 85.1 & 85.1 \\ \text { No } & 12 & 10.5 & 95.6 \\ \text { Not sure } & 5 & 4.4 & 100 \\ \text { Total } & 114 & 100 & \end{array}$

Source: Administered questionnaire (2016)

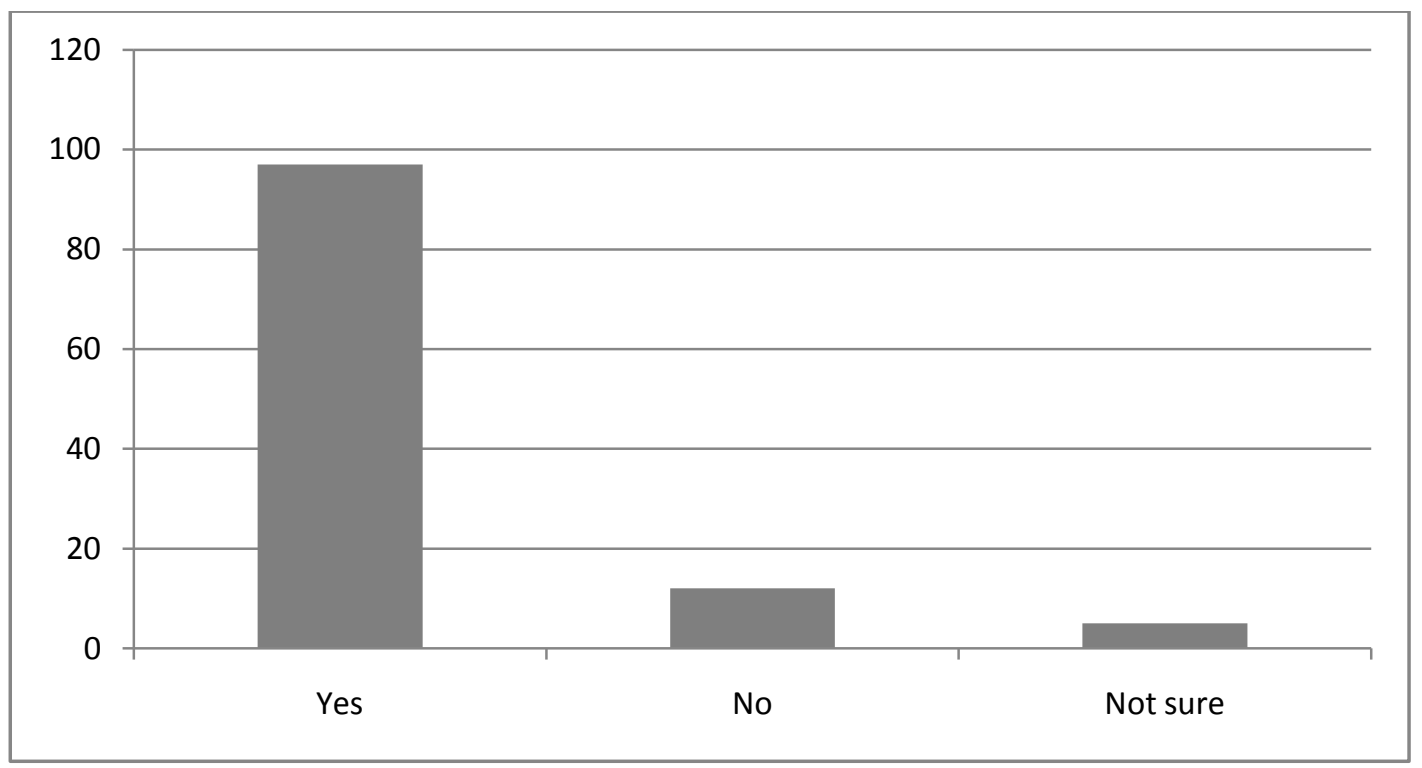

From the table and column chart above it was observed that the $97(85.1 \%)$ of the respondents replied that health information officers play their roles well for health information generation and utilization, $12(10.5 \%)$ of the respondents replied that they don't while 5(4.4\%) replied that they are not sure. With the response rate the fact that health information officers play their roles in the health information generation and utilization was asserted.

Research question 6: How often is health information being put to use for monitoring and evaluation of health care services? 
Table 13: The percentage distribution of responses according to number 20

$\begin{array}{llll}\text { Variable } & \text { Frequency } & \text { Percentage } & \begin{array}{l}\text { Cumulative } \\ \text { percentage }\end{array} \\ \text { Yes } & 98 & 86.0 & 86.0 \\ \text { No } & 3 & 2.6 & 88.6 \\ \text { Not sure } & 13 & 11.4 & 100 \\ \text { Total } & 114 & 100 & \end{array}$

Source: Administered questionnaire (2016)

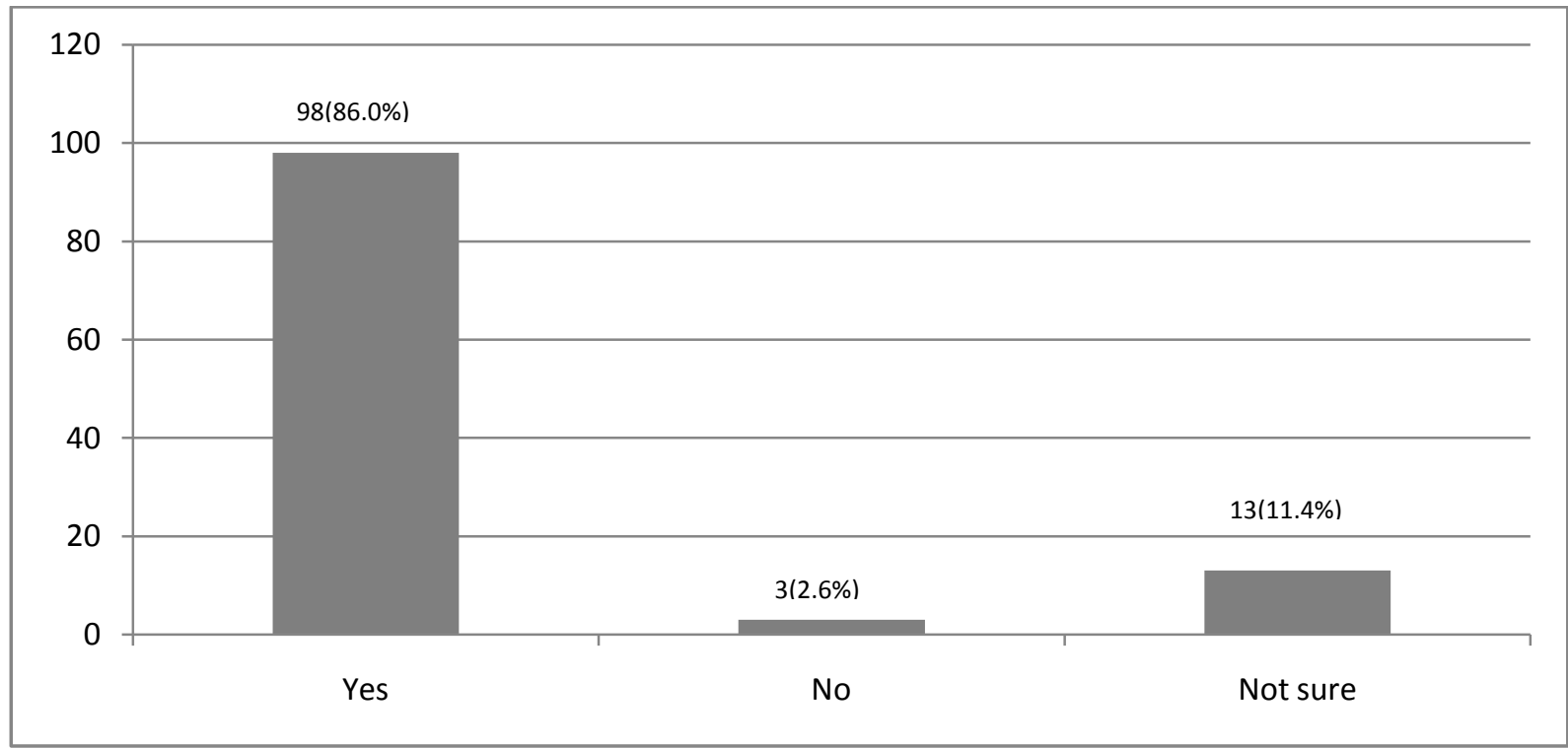

It can be deduced from the table and pie chart above that $98(86.0 \%)$ of the respondents which has the highest percentage, opined that health information is being put into use regularly for monitoring and evaluation of health care services, 3(2.6\%) did not agree and 13(11.4\%) were not sure. According to the response rate, it can be asserted that health information is being put into use regularly for monitoring and devaluation of health care services.

\section{Discussion of findings}

From the findings of the study, various observations were made. It was deduced that health information systems is impressive due to the opinion of majority of the respondents which denotes that health information systems contributes to good service delivery in Ife Central Local Government Area. 
It was affirmed that there are factors hindering effective management of health information systems by the respondents which was supported by $75.5 \%$ of them in their response to question 24 of the questionnaire.

Also, it was also discovered that health information systems has benefits on health care monitoring and evaluation which denotes it can be used in policy and decision making. The importance of health indicators (pointers) in monitoring and evaluation of a healthcare service facilitates accurate measurement of the healthcare delivery service for monitoring and evaluation system. This was confirmed in the responses to the questionnaire according to question 23.

It was also proved according to responses to question 21 of the questionnaire that the duties of the health information officers cannot be overrule and that they play their roles as expected for generation and utilization of health information. It was observed too that health information is being put into use regularly for monitoring and evaluation of health care service by the respondents in question number 20 of the questionnaire.

\section{Summary}

This study investigates the relevance of health information system in the monitoring and evaluation of health care service delivery in Ife Central Local Government, Ile-Ife, Osun State, Nigeria. Internets and textbooks were inquired to generate findings. Total enumeration of the respondents was used and one hundred and twenty questionnaires were administered to the workers of PHC Department Ife Central Local Government and one hundred and fourteen were retrieved, frequency table, simple percentage and charts were used for analyzing the results.

It was established that the role of health information officer cannot be ruled out in the health care service delivery and that health information systems have benefit on monitoring and evaluation of primary health care service delivery.

The study also confirmed that proper monitoring and evaluation of healthcare can be improved through adequate information, sufficient staff, provision of modern equipments, training and seminar, and provision of computerized based health information system in all the health information management units in order to boost efficient and effective patient care.

Finally, it was also deduced that factors that hinder effective management of health information systems include negligence in duty, inadequate staffing and inadequate funding which lead to insufficient information for monitoring and evaluation in the primary healthcare service delivery.

\section{Conclusion}

This study reveals that health information systems has great impact on healthcare service delivery, the system capture, store and transmit information related to patient care and the activities of the health institution. It incorporates routine information system, disease surveillance system, laboratory information system, hospital patient administrative system 
which is sued to process reports and create awareness in order to make policy action programmes that are effective for quality monitoring and evaluation activities.

\section{Recommendations}

In the course of this study, the following were suggested as recommendations.

- There is need for provision of sufficient and well trained staff that will work towards the generation of enough information for monitoring and evaluation of healthcare service.

- Constant seminar and training should be conducted for the health workers of the primary health care department of Health Information System Development and Management.

- Proper caution must be made to avoid constraints encounter during patient care which lead to inadequate information.

- The local government authority should provide adequate fund for procuring all necessary equipments contributing to patients care.

- There should be supervisory committee that will guide the implementation of the health information systems which will enhance good monitoring and evaluation should be set up.

- Computerization of all the various components of health information system in PHC department is also recommended for accurate and precise generation of information. 


\section{REFERENCES}

- Adediran, S. (2010) Unpublished document on Monitoring and Evaluation in Nigeria

- Adindu (2008) Health Information Ethics and Home. Published by World Health Organization.

- Aremu (2006) Introduction of Health Records Management published by decency printers, Nigeria

- Ball et al (1994) the healthcare professional workstation, USA

- Brailer and Thompson (2004) on Health Information Technology, Califonia

- Encyclolopedia Britannca (2012) Information system http://go.worldbank.org

- Google Consumer Healthcare (2008) http://en.Wikipedia.org/w/index

- Guidance for Monitoring and Evaluation of National Health Strategies, WHO 2010

- Health Management Information System 2010, Manual (Draft) MoH, 2010

- Health Sector Strategic and Investment Plan 2010/11 - 2014/15, MoH July 2010

- Health systems/IHP_M\&E_briefing_30_Jan_2008.pdf (accessed Jan. 22, 2010)

- Hospitals in a Changing Europe. Buckingham, Open University Press, 2002

- Hufman (1985): Medical Records Management printed by William Heineman Medical Books Ltd London

- Lippeveld, Sauerborn and Bodart, (2000). Design and Implementation of Health Information Systems, Geneva

- Monitoring and Evaluation of Health Systems Strengthening: An Operational Framework, WHO, GAVI, Global Fund and the World Bank, November 2009, Geneva

- Monitoring, Evaluation and Review of National Health Strategies: A country-led platform for information and accountability, WHO, May 2011

- Nancy LeMay (2010) Journal of Health Communication; supplement 1, 105-118, America

- Onyebuchi A, Arah TC, Klazinga NS (2003). Updating the Key Dimensions of Hospital performance: The Move towards a Theoretical Framework. Third Workshop on Hospital Performance Measurement, Barcelona

- Osundina (2008) Principle and Practice of Health Records Management published by K.S. Osundina Publications, Nigeria

- Ovretveit J. (2001) Quality Evaluation and Indicator Comparison in Health Care International Journal of Health Planning and Management, 16, 3:229-241

- Oxford English Dictionary (1995) complied by Joyce M. Hawkins

- Pacific Health Information Network (2011) on Health Information, University of Queenland, Australia

- Reichertz (1984) Medical Informatics, fifth congress of the European Federation for Medical Informatics, Brussels

- Renuke Bery in Batanlyn (2002)

- Shapiro Janet (2010) on Monitoring and Evaluation

- Sitzia J. (1999) How valid and reliable are patient satisfaction data? An analysis of 195 studies. International journal of quality in health care.

- Stanfield (2005) Bulleting of the WHO

- Verentson and co (1992). Monitoring and Evaluation manual

- Wikipedia.org/w/index.php

- World Bank (2011), on Health Information System

- World Health Organization Hospital Advisory Group, (1994). A review of the determinants of hospital performance. Geneva 
Journal DOI: www.doi.org/10.46654/AJBED

$$
\text { Vol. 1, Issue } 1 \text { (January, 2021) | www.ijaar.org }
$$

Article DOI: www.doi.org/10.46654/AJBED.7124

- National Primary Health Care Development Agency (2012). Development and Implementation Primary Health Care in Nigeria, published by Federal Ministry of health

- Osundina (2014) Legal and Ethical issues in the Management of Patient records in tertiary hospitals in Southwest Nigeria

- PHAST (2011) Information and Development 